\title{
Frantz Fanon e o ativismo político-cultural negro no Brasil: 1960/1980
}

\author{
Frantz Fanon and black political and cultural activism \\ in Brazil: 1960/1980
}

Mário Augusto Medeiros da Silva

\section{Introdução}

O sociólogo Antônio Sérgio Guimarães procurou refletir acerca da recepção brasileira da obra do psicanalista, pensador e ativista político martinicano Frantz Fanon (1925-1961) e, ao fazê-lo, chamou a atenção para o silêncio de intelectuais como Roger Bastide, Florestan Fernandes, Guerreiro Ramos, Sergio Milliet, Clóvis Moura ou Abdias do Nascimento (Guimarães, 2008: 100-105), que entre 1950 e 1960 não trataram de Pele negra, máscaras brancas, Os condenados da terra, Sociologia de uma revolução ou Em defesa da revolução africana, entre outros livros importantes do autor referentes ao processo colonial e seu combate revolucionário

Mário Augusto Medeiros da Silva é doutor em Sociologia pelo Instituto de Filosofia e Ciências Humanas da Universidade Estadual de Campinas (IFCH-Unicamp), São Paulo, Brasil. Agência de financiamento FAPESP (marioaugustomed@yahoo.com.br).

Artigo recebido em 30 de junho e aprovado para publicação em 4 de setembro de 2013.

Est. Hist., Rio de Faneiro, vol. 26, no 52, p. 369-390, julho-dezembro de 2013. 


\section{Mário Augusto Medeiros da Silva}

e ao impacto da colonização sobre o sujeito dominado. Referindo-se aos anos 1970 e 1980, Guimarães sugere ter havido uma espécie de recepção indireta dos livros fanonianos através de jovens ativistas negros, vários em contexto universitário, ou ainda por parte de intelectuais como Octavio Ianni, Paulo Freire e Abdias do Nascimento (Idem: 106 e 108), que, sofrendo o impacto da ditadura civil militar, tomaram contato com a obra em situações diversas.

Os textos de Fanon mais conhecidos circularam, foram publicados e traduzidos no Brasil mais ou menos nesse intervalo de tempo - em 1968 e 1979 saíram a $1^{\mathrm{a}}$ e a $2^{\mathrm{a}}$ edição de Os condenados da terra, pela Civilização Brasileira; em 1980 saiu a tradução portuguesa de Em defesa da revolução africana; em 1983 saiu $1^{\text {a }}$ edição brasileira de Pele negra ${ }^{1}$, , o que permitiria o acesso desses novos leitores, seja de maneira direta, seja de maneira indireta, através de textos sobre as lutas civis nos EUA ou a descolonização da África Portuguesa, como afirma Guimarães e como procurei demonstrar em trabalho anterior (Silva, 2011: 294-303), discutindo a recepção dessas temáticas através da seção Afro-Latino-América do jornal Versus.

Lançado por Marcos Faermann, Versus publicou em suas páginas matérias referentes à Africa Negra, facultando a seus leitores, entre outubro de 1975 $\left(n^{\circ} 2\right)$ e junho de 1977 ( $\left.{ }^{\circ} 11\right)$, tomar contato com a arte de máscaras negro-africanas (com o documentarista francês Chris Marker); com as origens e o desenvolvimento do apartheid na África do Sul; com os processos de luta anticolonial em Guiné-Bissau e Angola; com o pensamento dos líderes revolucionários Agostinho Neto e Mário de Andrade (Angola), Amílcar Cabral (Cabo Verde) e Eduardo Mondlane (Moçambique); ou, ainda, com o exílio de José Celso Martinez Corrêa e Celso Luccas em Moçambique, que resultaria na produção do filme 25, dirigido por ambos, sobre a revolução naquele país. Em 1977, Faermann convidou seu colega do jornal $O$ Estado de S. Paulo, o escritor e jornalista negro Oswaldo de Camargo, ${ }^{2}$ para criar a seção Afro-Latino-América. Dessa forma, o Brasil negro entraria nas páginas de Versus. ${ }^{3}$

Note-se que Pele negra foi publicado originalmente em 1952 e sua tradução brasileira aconteceu três décadas depois, embora, como demonstrou Renato Ortiz (1986: 45-67), ${ }^{4}$ seu autor tivesse circulação pelo Iseb; já Os condenados da terra, comparativamente, teve circulação quase imediata, em função da visita de Sartre e Simone de Beauvoir ao país em 1960 (Romano, 2002). Mentor intelectual de Fanon, Sartre foi também o divulgador de sua discussão sobre o processo colonial. Acrescento que ainda em 1968 a Biblioteca Tempo Universitário traduziu e publicou Colonialismo e neocolonialismo, quinto volume da série Situações, em que Sartre trazia dois textos importantes para essa discussão: “Os malditos da terra”, prefácio que escreveu para a edição francesa de Os condenados, em 1961, e "O pensamento político de Patrício Lumumba" [sic], escrito para os Discursos de 
Lumumba, publicados pela Présence Africaine. Neste último, Sartre analisava Fanon e Lumumba, ambos mortos entre 1960 e 1961, vendo-os como duas faces não opostas da luta anticolonialista (Sartre, 1968: 137-205).

Em seu texto, Guimarães (2008: 111) afirma: “Mas a primeira reflexão mais sistemática (e talvez única) sobre o pensamento de Fanon feita por intelectuais negros numa revista acadêmica brasileira aconteceu apenas em 1981 e foi assinada por um coletivo, Grupo de Estudos sobre o Pensamento Político Africano (GEPPF), o que denota tratar-se de um meio caminho entre reflexão acadêmica e reflexão política". Este artigo visa acrescentar a essa discussão outra via de circulação das ideias de Fanon no Brasil: entre os ativistas e escritores negros dos anos 1980. Embora pouco conhecida, essa discussão teria consequências interessantes para o debate sobre a literatura negra brasileira e o papel do intelectual que a produz.

\section{Um contexto lacunar: indícios de África no horizonte}

A circulação de ideias sobre África ou de intelectuais e militantes africanos em São Paulo ainda carece de pesquisas mais articuladas. Memórias como as do militante José Correia Leite (Leite \& Cuti, 1992) ou entrevistas como a de Oswaldo de Camargo (2007) mostram que, entre os anos 1920 e 1960, as associações negras paulistanas tiveram contatos esparsos com obras traduzidas, ${ }^{5}$ escritores, ${ }^{6}$ jornalistas ${ }^{7}$ e debates que remetiam a temas como o pan-africanismo, os movimentos que visavam ao retorno ao continente africano, as lutas anticoloniais e pela libertação de países, a violência do apartheid etc. Contudo, dada a exiguidade de outras memórias ou de documentações semelhantes, a verificação do grau de penetração e uso desses pensamentos ficou prejudicada.

Por exemplo: Frantz Fanon participou do I e do II Congresso de Escritores e Artistas Negros, realizados em 1956 (Sorbonne) e 1959 (Roma) e patrocinados pela revista Présence Africaine e pela Société Africaine de Culture. Do segundo encontro (Silva, 2011: 186-187) participou Geraldo Campos de Oliveira, representando a Associação Cultural do Negro (ACN). ${ }^{8}$ Qual foi a apreensão do debate por aquele militante e pela $\mathrm{ACN}$ não foi possível, até o momento, aferir precisamente, em função das lacunas das fontes primárias e da ausência de fontes orais.

Por outro lado, nas entrevistas coletadas por Verena Alberti e Amílcar Pereira (2007), têm-se, em diferentes momentos, aspectos da apreensão de ideias semelhantes entre ativistas e intelectuais negros dos anos 1970 e 1980 . Nomes do movimento político e cultural negro como Amauri Pereira (da Sociedade de Intercâmbio Brasil-África), Luiz Silva (conhecido como Cuti, criador dos $C a$ - 


\section{Mário Augusto Medeiros da Silva}

dernos Negros e do Quilombhoje), Ivair Augusto dos Santos (ligado ao Movimento Negro Unificado e ao Conselho de Participação e Desenvolvimento da Comunidade Negra de São Paulo), entre outros, relatam suas leituras de autores como Fanon, Amílcar Cabral ou Agostinho Neto. Representantes do ativismo negro estadunidense mencionam leituras de Eldrige Cleaver, Malcolm X, Angela Davis etc. Nesse caso, é possível ainda verificar de que maneira essas leituras e as ideias debatidas operacionalizaram as ações desses intelectuais e as associações mais novas no Brasil, por estarem eles mais próximos no tempo, sendo possível entrevistá-los e checar seus arquivos, razoavelmente preservados.

\section{O debate nos anos 1980: em busca de uma estética e politica negra}

Aspectos da obra de Fanon foram apropriados no ativismo político-cultural negro dos anos $1980 \mathrm{em}$ ao menos três ocasiões pelo mesmo escritor, pertencente ao coletivo Quilombhoje. ${ }^{9}$ Em "Questões sobre a literatura negra" (1985), "A forma escura" (1986) e nominalmente em "O sentido da literatura negra, sob uma abordagem fanoniana” (1987), Márcio Barbosa ${ }^{10}$ tenta dimensionar seu entendimento acerca do que seja uma literatura negra brasileira, a partir de aspectos da concepção fanoniana sobre como é construído o sujeito social negro, chegando a conceber a formulação de uma literatura afro-brasileira como nomenclatura mais adequada para a confecção artística dos escritores.

Suas fontes bibliográficas citam, entre outros, Os condenados da terra (1979), com o texto "Sobre a cultura nacional", e "Racismo e cultura", publicado em tradução portuguesa em 1980 no livro Em defesa da revolução africana. Esse livro é o original Pour la révolution africaine, conjunto de ensaios dispersos editado pela François Maspero em 1969 e traduzido em Portugal pela Sá da Costa Editora, na Colecção Terceiro Mundo. "Racismo e cultura" é a conferência de Fanon no I Congresso de Escritores e Artistas Negros, em 1956; "Sobre a cultura nacional" é sua conferência de 1959, para a segunda edição do evento.

Em "Questões sobre a literatura negra", Barbosa afirma que não existirá literatura negra e escritores negros no Brasil enquanto não houver uma consciência negra que rompa com a consciência do oprimido (consequentemente, do opressor) e deixe de ser duplamente conservadora (imitação da literatura opressora, querendo ser legitimada enquanto tal). Nesse texto em particular, Barbosa usa o léxico fanoniano com a intenção de demonstrar que: 1) a literatura negra existe em larga razão pelo fato de haver sua contraparte branca; 2) criada numa posição subalterna e oprimida, à literatura negra resta o desenvolvimento de uma autoconsciência, fundada no desenrolar da luta histórica do grupo negro contra sua condição de oprimido. 
Em que momento se pode dizer que surge uma literatura negra? Seu argumento paulatinamente se sofistica, alcançan do a espinhosa discussão da dupla consciência do escritor negro - desenvolvido do repertório fanoniano sobre a dupla consciência do intelectual colonizado. No que tange ao escritor, o problema se dá na forma e conteúdo expressivos. O escritor negro, para se libertar do molde de sua contraliteratura, deveria criar uma nova forma de expressão, não conservadora como sua contraparte. Além disso, de acordo com a interpretação de Barbosa, ele deve conscientizar-se de sua condição, historicamente subalterna, para poder se libertar.

Por isso a existência de uma literatura negra é posterior à existência de uma consciência negra. Como a arte do opressor é, em si, conservadora, a arte do oprimido, como seu reflexo, vai ser duplamente conservadora. Só que a arte do oprimido não é, em si, conservadora. Ela é conservadora apenas enquanto reflexo da arte do opressor. A arte do oprimido, quando este se dá conta do seu papel como agente histórico é, em sua essência, transformadora, pois o oprimido é o agente social que não tendo mais nada a perder não se vê comprometido inteiramente com esta sociedade e assim é o único que pode transformá-la. Desse desejo de transformação é que surge a transformação das formas e como consequência a forma de uma literatura negra (Barbosa, 1985: 51).

Barbosa publicará depois "O sentido da literatura negra, sob uma abordagem fanoniana", comentário sobre as ideias daquele autor, atualizando-as para o contexto e uso brasileiros. Acrescento assim mais uma hipótese aos argumentos de Guimarães: talvez a circulação e a recepção de Fanon no Brasil se tenham dado ao fim dos anos 1970, através do interesse dos intelectuais e ativistas negros focados nos usos possíveis que suas ideias poderiam ter para suas lutas político-culturais no contexto nacional. Ou seja: menos pela ação política direta (visando à revolução), e mais pela reversão simbólica, histórica e cultural, acerca do grupo social negro no Brasil. Assim, é necessário pensar sobre o que fez Márcio Barbosa encontrar a reflexão de Fanon, justamente acerca do papel do intelectual, do pensamento e da arte colonizadas.

\section{Qual Fanon, para qual intelectual e em que contexto?}

"Sobre a cultura nacional" mostra um intenso debate sobre as tarefas do intelectual colonizado, do escritor no processo de luta pela descolonização, 


\section{Mário Augusto Medeiros da Silva}

e sobre a criação de uma expressão nacional autêntica. É um comentário posterior ao texto "Fundamentos recíprocos da cultura nacional e das lutas de libertação". Nele estão expostos alguns tópicos que, aos olhos de um militante político e da cultura negra nos anos 1980, encontrariam similitude com o contexto brasileiro.

O texto se inicia com o apelo para que se pare de julgar o passado com os olhos do presente, e se procure balancear os alcances e limites das ações dos sujeitos sociais em cada época em face dos desafios encontrados em seus momentos específicos, uma vez que "cada geração deve, numa relativa opacidade, descobrir sua missão, executá-la ou traí-la"; ${ }^{11}$ a seguir, faz-se uma longa discussão acerca do papel do homem de cultura colonizado (intelectuais, escritores etc.) e sua relação com a memória social, a reconstrução ou "recuperação" do passado nacional, ${ }^{12}$ o que significa a construção de uma identidade alternativa à do dominado/subalterno. O trabalho com a memória (ou sua tentativa de reconstrução) revelar-se-á, segundo Fanon, um processo de reencontro com o povo e, portanto, a inauguração de um devir. Reencontro muitas vezes oblíquo e dramático, causando estranhamento a um e a outro lado, e que se daria em três etapas: assimilacionista, ${ }^{13}$ memorialista, ${ }^{14}$ e combativa; ${ }^{15}$ e o homem de cultura teria completado seu processo de descolonização ou reação à dominação intelectual, fazendo de sua literatura uma arma potente.

Fanon, no entanto, alerta que o intelectual em todo esse processo é uma espécie de sujeito fora de lugar (um estrangeiro), ${ }^{16}$ autoatribuindo-se uma missão, geralmente estranha ao povo concreto que busca encontrar, representar e provocar. Embora estranhada sua tarefa e papel, ele dever ser o propulsor de um devir em aberto. Em síntese: seu ativismo político-cultural enquanto "homem colonizado que escreve para seu povo, deve, quando utiliza o passado, fazê-lo com o propósito de abrir o futuro, convidar à ação, fundar a esperança" (Fanon, 1979: 193). O futuro em aberto, mas ideado pela luta declarada e armada contra o sistema colonial e sua opressão.

De que forma isso chega ao Brasil? Márcio Barbosa afirma que tinha interesse em estudar efetivamente a obra de Fanon na USP, como conta a seguir:

Sim, eu lia muito o Fanon nessa época. Pele negra, máscaras brancas, Em defesa da revolução africana, Os condenados da terra. $\mathrm{O}$ Fanon eu acho que foi muito importante pra mim nessa época. Eu queria até fazer uma tese sobre o Fanon, na verdade. Na época, eu até procurei o falecido Clóvis Moura pra ser meu orientador, mas ele falou que não "manjava" de Fanon e falou que não poderia ser. E aí, acabei deixando de lado. Até é uma discussão que a gente tem hoje em dia, que é uma coisa que o Cuti [Luiz Silva] levanta, que é essa questão da literatura negra ou 


\section{Frantz Fanon e o ativismo politico-cultural negro no Brasil}

literatura afro-brasileira. Que eu acho que é uma coisa, pra mim, que vem de Fanon. Que ele fala 'negro só se torna negro a partir do domínio do branco'. Porque você não tinha um negro, você tinha o africano, você tinha lá o zulu, você tinha o haussai, enfim mina, esse tipo de coisa. E Fanon fala isso. Então, eu acho que é por aí também. Negro só se torna negro a partir do domínio do branco. É a identidade contraposta (Barbosa, 2010).

A positividade do passado atribuída por Fanon enquanto busca pela autenticidade, uma história anterior à colonização, identidade contraposta, é interessante para pensar o papel social que a memória coletiva terá nessa discussão. $\mathrm{O}$ colonizado foi inventado pelo colonizador, tanto quanto o dominado pelo dominante. Antes de tudo, o subalterno era um humano, um sujeito social. Daí a perspectiva fanoniana encerrar, fundamentalmente, uma aposta na ideia de cultura, angulada pela ótica do colonizado ou oprimido, como motor da resistência e da construção de uma situação social alternativa e emancipatória. A cultura nacional é pensada sob certo signo de autenticidade original ou de pertencimento, alternativa e anterior à imposição do opressor ou colonizador. Justifica-se, então, a importância atribuída pelo autor ao processo de recuperação da memória como etapa necessária para romper e sobrepujar os valores do opressor. "A situação colonial determina, em sua quase totalidade, a cultura nacional" (Fanon, 1979: 198). E se a luta pela cultura nacional possui fundamentos recíprocos com as lutas de libertação, subentende-se que, naquele quase, há um intervalo onde a memória, o ativismo político-cultural e - no contexto de seu pensamento - a luta revolucionária operam.

A conferência de 1956 no I Congresso de Escritores e Artistas Negros, "Racismo e cultura", tratará disso em alguma medida, e será outro texto base para Barbosa, que citará literalmente suas passagens. Fanon discute o racismo não enquanto uma doença da humanidade ou algo particular de certos grupos humanos, mas como uma forma cultural, uma estrutura social de relações, hierarquista e etnocêntrica.

O racismo não é um todo, mas o elemento mais visível, mais quotidiano, por assim dizer, o mais grosseiro de uma dada estrutura [...] Estudar as relações entre o racismo e a cultura é questionar sua ação recíproca. Se a cultura é o conjunto dos comportamentos motores e mentais, nascidos do encontro entre o homem e a natureza e seu semelhante, deve-se dizer que o racismo é um elemento cultural. Há, portanto, culturas com racismo e culturas sem racismo (Fanon, 2001: 39-40. Tradução minha). 
O racismo enquanto elemento cultural opõe formas de existência.$^{17} \mathrm{E}$ a forma do dominante quase determina totalmente a forma do dominado, tornando-o um objeto do sistema colonial/opressivo. Entretanto, o autor afirma existir um intervalo em aberto para a tomada de consciência coletiva, que passa a ser o da resistência à opressão da forma dominante. Uma luta intestina, que se oporá à sofisticação crescente do racismo - este, chegando a se invisibilizar na sociedade para diferentes sujeitos sociais, como se ele não existisse ou se vivesse numa democracia racial, por exemplo; ou, em seus termos, a forma de existência racista se tornará uma ideologia democrática e humana, fundada silenciosamente na superioridade de um modo de vida sobre outro.

\section{Uma leitura de Fanon: o dilema do escritor negro brasileiro}

A luta contra o racismo possui um componente de luta cultural. Em Fanon não há racismo inconsciente, mas um processo paulatino de construção das formas culturais racistas, que coloca o dominado na posição de subserviência e submissão. Constrói-se assim uma relação de culpabilidade e inferioridade para o dominado, que se torna conscientemente inferiorizado e irreconhecível, deslegitimado socialmente, uma vez que "o racista numa cultura com racismo é normal” (Fanon, 2001: 47. Tradução minha).

Sendo o racismo um elemento, um modo de existência hierarquizado, e sendo a luta contra a dominação e a opressão desse elemento e modo uma luta cultural, o intelectual, os homens de cultura dominados, terão como tarefa construir e legitimar, redescobrir e potenciar a memória e o passado, as formas de existir consideradas as mais verdadeiras do dominado. Márcio Barbosa, em sua leitura de Fanon, interpretou que essa tarefa consistiria em pensar o modo negro, brasileiro, de estar no mundo:

[...] quando um autor negro procura seu universo na experiência artística de uma África antiga, será logo chamado de retrógrado. Quando um autor negro procura a dimensão mítica da experiência religiosa afro-brasileira, seu trabalho só obterá repercussão se submeter-se à folclorização. Se esse autor recorrer ao conteúdo revolucionário da literatura de Angola ou Moçambique provavelmente será acusado de ser no mínimo um alienado. Ora, é evidente que o autor negro necessita formar um acervo de onde extrair matéria para as suas criações e quando procura formar esse acervo na experiência secular ancestral de seu povo originário, isto é, os africanos, vê-se repentinamente cercado de limitações (Barbosa, 1986: 130). 
O que remete ao texto fanoniano, permitindo assim a comparação das tarefas impostas:

Esta cultura, abandonada, extirpada, rejeitada, largada, nela o inferiorizado se engaja com paixão [...] Os costumes, tradições, crenças anteriormente negados e passados em silêncio são violentamente valorizados e afirmados. A tradição não é mais ironizada pelo grupo. $\mathrm{O}$ grupo não se ri mais. Retoma-se o sentido do passado, o culto dos ancestrais... (Fanon, 2001: 48-49. Tradução minha).

Aposta-se na ideia de cultura, na luta pela reversão simbólica da prática quotidiana de pensar e agir, de ser e estar no mundo, da afirmação e reconhecimento das formas de existência várias, de um embate entre diversidade e desigualdade, visando um universalismo emancipatório. "Concluindo, a universalidade reside na decisão de apoiar o relativismo recíproco das diferentes culturas uma vez excluído irreversivelmente o estatuto colonial" (Fanon, 2001: 51. Tradução minha). Fanon impõe a seu pensamento e leitores, intelectuais ou militantes, tarefas formidáveis, mas consideradas possíveis. Apostando na cultura - ou numa luta cultural que forme outras relações sociais - o autor formata um pensamento antirracista para uma sociedade em construção, com base humanista.

Esses comentários permitem refletir sobre a circulação das ideias de Fanon num circuito alternativo e pensar seu uso no interior do Quilombhoje, num momento de coesão daquele grupo. Ao se centrar n' "O sentido da literatura negra, sob uma abordagem fanoniana", Barbosa se impôs o desafio proposto pelo pensador martinicano de se refletir enquanto homem de cultura dominado; o que, nos textos fanonianos lidos, anuncia a procura final de uma perspectiva universalista (e não só para o contexto africano). Sua interpretação é:

Se existe alguma identidade entre a análise que Fanon desenvolve e a realidade social brasileira, isso se deve ao fato de que Fanon ao desvendar o racista sistema colonial consegue captar a existência do negro (enquanto indivíduo, grupo ou classe étnica) dentro das formas de relação social instaladas a partir do domínio branco-europeu e a transformação destas formas na moderna sociedade industrial, crescentemente técnica e burocratizada [...] No caso brasileiro, poderíamos dizer que isso corresponde a uma recuperação das lutas antiescravagistas, dos quilombos e rebeliões dos séculos passados, culminando com o mergulho apaixonado na história de Palmares e a institucionalização de um 


\section{Mário Augusto Medeiros da Silva}

herói negro; além disso há a tentativa de redescobrir as estruturas religiosas tradicionais e recuperar as histórias das artes e cultura africanas do passado. [...] Vemos então que a importância do homem de cultura não é assim tão restrita. $\mathrm{O}$ negro que cria o hábito de dirigir-se a outro negro, tendo como tema a luta cotidiana, política ou armada, engendrada no sentido de destruir estruturas racistas, estabelece uma relação fértil e um processo de mobilização intensa (Barbosa, 1987: 118-120).

É fato que há certa dificuldade em acoplar o pensamento de Fanon à realidade negra no Brasil, em função do contexto em que ele é produzido. Entretanto, o tema da missão do homem de cultura dominado, de que ele tenha tarefas e que, no caso do intelectual negro, elas se situem na reversão simbólica e concreta da prática quotidiana, parece possível absorver, para seu intérprete brasileiro, com algumas precauções. ${ }^{18}$

O escritor e intelectual negro no Brasil são sujeitos fora de lugar (tanto quanto o africano de que fala Fanon). No caso dos Cadernos Negros e do Quilombhoje, ou de outras iniciativas político- culturais, ele se vale continuamente da memória como elemento potenciador de suas ações, após longo processo de tentativas de encontrar seu povo. Assim se anuncia em Barbosa o pensamento fanoniano em "A forma escura":

Podemos ter nostalgia de um tempo passado, podemos até sentir banzo; podemos chegar por um esforço de vontade e uma subversão ao que nos foi específico. Porém, não nos é permitido ignorar este acúmulo de fatos e conhecimentos derivados da Ásia e Europa, os quais também passam a nos pertencer. Contudo, essa é uma paisagem que não satisfaz e, havendo outra possível, somos obrigados a procurá-la [...] Naufraguei várias vezes mas voltava ileso, e o primeiro naufrágio sem retorno ocorreu quando li um poeta africano. Nesse livro havia a essência que eu procurara anteriormente em outros autores [...] Então, desde essa primeira leitura, tudo já estava dado. A identidade dos problemas sociais e raciais punha-nos, a mim e ao poeta, numa mesma comunidade universal. [...] Mas, além disso, e talvez mais importante, existia a perspectiva de uma experiência diferenciada, de uma literatura produzida a partir de outro material básico (Barbosa, 1986: 126-128).

Que outro material é este de que fala o autor? Ele evidencia que se trata das apreensões, a posteriori, pelo escritor, do que seria a vida de seu grupo social no Brasil. ${ }^{19}$ Contudo, entre o vivido e o narrado existem ao menos dois proble- 
mas: o das formas de viver e o das formas de dizer. Quem é o escritor de literatura negra e de que linguagem ele se vale para sua confecção literária? Barbosa nos oferece uma resposta, no contexto das discussões dos anos 1980.

Representamos uma classe de pessoas condenadas à desvantagem [...] Em primeiro lugar, não temos uma linguagem diferente da linguagem que comumente se fala. Mas temos a possibilidade de alterar o significado das palavras, pois a linguagem é viva. [...] Determinados vícios nós ainda temos que superar, por exemplo, nós raramente lemos os livros uns dos outros. Isso é manifestamente o sinal de uma pobreza intelectual e política muito grande [...] Talvez falte-nos também a ousadia de ir um pouco além do que conhecemos, a ousadia de inventar, de desligarmo-nos do que está consagrado pelo uso. Mas, para desligarmo-nos, temos que conviver com a possibilidade do erro e essa é grande. [...] [Para] relembrar Fanon: "A luta do inferiorizado situa-se a um nível nitidamente mais humano. As perspectivas são radicalmente novas. Só assim poderá a arte ser outra" (Barbosa, 1987: 132-133.) ${ }^{20}$

\section{Sob a sombra de Fanon: as tarefas do intelectual negro brasileiro}

Linguagem, memória, história "autêntica"; missão do homem de cultura, abrir o devir, vinculação com o povo; literatura e política, reversão e recriação do quotidiano; necessidade de calibrar as formas de dizer e precisar a experiência para uma representação mais próxima das formas de viver do grupo social, original/leitor-ideal. Findos os encontros de escritores negros brasileiros, em que tais ideias circularam, publicadas em 1986 e 1987, era de esperar que as produções dos autores em Cadernos Negros, ou que a configuração do grupo Quilombhoje se pautassem por aquelas questões e tentativas de definições.

Analisando a produção do Quilombhoje desse período, verifica-se que o volume 11 de Cadernos Negros tem montagem feita com uma série de fotografias de crianças, interna e externamente, e que seus nomes são majoritariamente africanizados (com seus respectivos significados). As "Nossas Crianças", afirma o texto da orelha, são "agentes, atores, herdeiros de uma realidade histórica. Nossas crianças não-abandonadas, representantes da certeza de uma trajetória que não começa nem termina com elas". Pensando esse embate, da afirmação de um modo de existência e da necessidade de um devir, do reconhecimento do diverso simultaneamente à luta contra o desigual, publica-se exemplarmente o poema "Palavra de ordem", do gaúcho Oliveira Silveira: "Negro e proletário./ Bom ser 


\section{Mário Augusto Medeiros da Silva}

negro/ ruim ser proletário./ Bom ter esta cor,/ este jeito, este som./ Ruim ter esta fome, o frio, este não ter./ Manter a raça,/ Mudar a classe.” (Cadernos Negros, 1988: 55).

A palavra de ordem final se faz ouvir com mais intensidade na produção de outros autores publicados em 1990, no volume 13:

No princípio era a pólvora e a sífilis/ variadas gonorréias e o chumbo/ abençoados pela hipocrisia mística/ Com o tempo/ chegou-se à bomba atômica/ inúmeras armas químicas/ confeitadas de cocaína/ (prole numerosa/ aidéitica e cancerígena)/ primeiro mundo e seus ultimatos:/ aos primitivos tecnologia e nada/ sequestro do ori/ raízes amputadas (Cuti, “Civilization”, p. 27).

A voz de minha bisavó ecoou/ criança/ nos porões do navio./ Ecoou lamentos/ de uma infância perdida./ A voz de minha avó/ ecoou obediência/ aos brancos-donos de tudo./ A voz de minha mãe/ ecoou baixinho revolta/ no fundo das cozinhas alheias/ debaixo das trouxas/ roupagens sujas dos brancos/ pelo caminho empoeirado/ rumo à favela./ A minha voz ainda/ ecoa versos perplexos/ com rimas de sangue e fome./ A voz de minha filha/ recolhe todas as nossas vozes/ recolhe em si/ as vozes mudas caladas/ engasgadas nas gargantas./ A voz de minha filha/ recolhe em si/ a fala e o ato./ O on tem - o hoje - o agora./ Na voz de minha filha/ se fará ouvir a ressonância/ o eco da vida-liberdade (Conceição Evaristo, "Vozes mulheres", p. 32-33).

sonho cultivado em terra forte/ futuro crescendo num tronco firme/ amanhã kilumba/ o sol brincará de kizomba em teu riso/ colhendo primavera cheia de amores/ teu suplício teve curso desviado/ rua favela viaduto febem.../ não conhecerão tuas dores (Oubi I. Kibuko, "Camila", p. 70).

na minha verde-clara infância/ vestido em fantasia eu imitava/ batman, capitão américa, superman.../ hoje, maduro e escurecido/ trajando realidade sigo Zumbi/ Agostinho Neto, Luther King, Mandela.../ imortais guerreiros do meu povo (Oubi I. Kibuko, "Reais heróis", p. 71).

Contra o sequestro do ori (o orixá da cabeça, a energia vital) promovido pela civilização até a negação do caminho trágico legado pelo passado, seguindo líderes revolucionários negros: estariam explicitadas algumas das tarefas daqueles intelectuais negros. Outro caminho seria retomar a discussão sobre o papel dos ín- 


\section{Frantz Fanon e o ativismo politico-cultural negro no Brasil}

dices negros, esperados em relação à literatura publicada e publicável nos Cadernos. Tais índices, marcadores da diferença, operarão também nas concepções sobre o que seria uma literatura negra ou literatura afro-brasileira, eviden- ciando um projeto de comunicação entre o escritor negro e seu público imagi- nado.

Sobre isso, têm-se duas visões conflituosas na nomenclatura, mas que se coadunam no propósito de marcar a diferença da produção cultural.

É difícil você conceituar o que é literatura negra até hoje. Cada um tem uma opinião. Eu prefiro o termo afro, eu acho que o termo negro tem uns usos, o termo afro tem outros, e eu, atualmente, prefiro mais o termo afro-brasileiro. Mas acho que uma das coisas que a gente sempre teve muito bem explícito é que, realmente, a literatura negra tem que refletir a vida do nosso povo, a vivência do povo negro, isso eu acho que é consenso, hoje é consenso. [...] Eu acho que, quem trabalha com cultura, eu acho que tem mais a ver a questão afro, tem mais a ver a transcendência, é uma questão até on tológica mesmo. Quer dizer, a gente pertence a uma matriz, a gente pertence a um povo, a gente pertence a uma história (Barbosa, 2010).

Quando nós nomeamos [literatura] negro-brasileira, nós estamos trabalhando com o termo negro. Porque este termo, para a população negra, é um termo que remete às conquistas. Frente Negra, Dia Nacional da Consciência Negra, Movimento Negro... Então, quando eu chamo essa produção de literatura negro-brasileira, é exatamente isso, porque eu estou estabelecendo links com a conquista e com a existência da população. O nome, ele tem essa função. $\mathrm{E}$, ao no- mear literatura afro-brasileira, você apaga o negro. E, ao apagar o negro, você apaga todas as conquistas do movimento negro. Como eu disse, não é "dia nacional da consciência afro-brasileira", é o "dia nacional da consciência negra", não foi "Frente Afro-brasileira", foi "Frente Negra Brasileira", não se fala em "imprensa afro-brasileira", se fala em "imprensa negra". Então, por que que a literatura tem que abrir mão da palavra negro, sendo que esta palavra, ela é uma palavra que é uma palavra geradora. Se você fosse capaz de pegar todos os livros de autores negros e jogar no computador, e dizer lá quantas vezes aparece a palavra negro, você diria que inúmeras vezes. Porque essa palavra, ela é o cerne. Essa palavra, ela remete exatamente à questão existencial do negro no Brasil (Cuti). ${ }^{21}$

A tensão entre os termos negro e afro-brasileiro não é apenas um embate de nomenclatura entre um dos criadores da série Cadernos Negros (Cuti) e o seu con- 


\section{Mário Augusto Medeiros da Silva}

tinuador há mais de 30 anos (Barbosa). Ao contrário, trata-se de um sinal de disputas políticas e culturais mais amplas no interior do ativismo negro, em perspectiva histórica (cf. Pereira e Alberti, 2007). Não são questões fáceis de enunciar, e sobre elas não há consenso pacífico, a não ser a necessidade de retratar a vida do negro, esta estranhamente conhecida por todos, mas particularmente escrita por alguns. Esses escritores e intelectuais promovem a passagem física de personagens a autores negros, na literatura brasileira, onde os textos se tornam consequência do processo. Operam, neste sentido, uma das tarefas do sujeito de cultura negro, anunciadas por Fanon.

\section{A memória coletiva como projeto político do intelectual negro}

Quando apostamos nesta nossa iniciativa, estávamos conscientes do fazer literário e, ao mesmo tempo, histórico. Também sabíamos da necessidade de afastar o silêncio opressivo sobre a memória; conquistar para nossas vidas a perenidade da palavra impressa; revisitar e divulgar nossos autores, recuperando o sentido de uma tradição literária; alertar o Movimento Negro para a necessidade de valorização da leitura, para o poder que tem a literatura de mover em profundidade as pessoas; romper com a subserviência estética; incentivar a busca dos parâmetros da literatura da diáspora africana; subsidiar as novas gerações com este mergulho na cor da pele, revelando seu conteúdo simbólico, sua dimensão humana; impulsionar e valorizar a subjetividade do contingente afro-brasileiro; não ter papas nas letras ao falar do racismo e suas variadas escamoteações verde-amarelas. (Um pouco de história, Cadernos Negros, vol. 16, 1993)

No projeto do ativismo político-literário dos Cadernos Negros e do Quilombhoje, do final dos anos 1980, marcar a diferença não era o bastante. Ela deveria ter uma operacionalidade política. De certa maneira, delineia-se um sentido de missão autoatribuída por seus participantes como sujeitos de cultura. ${ }^{22} \mathrm{Re}-$ tratar o ambiente da Frente Negra Brasileira, como no conto de Aristides Barbosa ("Tia Frenê e o frentenegrino", Cadernos Negros, vol. 16); ficcionalizar uma tentativa de cobrar uma dívida histórica da sociedade para com os negros ("Dívida em vida", de Cuti, vol. 16); ou, ainda, tentar afirmar autoimagens positivas para o grupo social e o leitor ideal negros, que não tivessem mais a figura do "branco" como elemento de oposição: busca-se fazê-la desnecessária, para que se encontrem razões e modos de ser no próprio mundo do negro, como nos poemas 
abaixo, que reflitam criticamente sobre o passado e o presente daquele grupo social.

Paissandu a Praça/ Passo no Paissandu/ a Praça/ há Pedra/ há/ Rosário Negro a desfiar.../ há história/ Paissandu a Praça/ Passo/ Ouço/ Rosário rezado/ reisado/ negro a desfiar.../ há história em gêge/ praça pedra a pedra/ conta/ a/ conta/ Conta/ das costas que não se curva$\mathrm{ram} / \mathrm{conta} / \mathrm{ah}$ !/ conta/ apesar da cruz (crista cristã) pesar/ apesar/ conta/ Rosário rezado/ Reisado nagô/ conta a conta/ conta. (Miriam Alves, "Passo, praça", Cadernos Negros, vol. 17, 1994)

Não vou às rimas como esses poetas/ que salivam por qualquer osso./ Rimar Ipanema com morena/ é moleza,/ quero ver combinar prosaicamente/ flor do campo com Vigário Geral,/ ternura com Carandiru,/ ou menina carinhosa/ trem pra Japeri./ Não sou desses poetas/que se arribam, se arrumam em coquetéis/e se esquecem do seu povo lá fora. (Éle Semog, "Outras notícias”, Cadernos Negros, vol. 19, 1996, p. 55)

Como se tentou demonstrar até aqui, trata-se de um percurso complexo esse momento do coletivo de escritores. Diversas direções parecem se afunilar num único sentido. De personagem o mais das vezes estereotipado na literatura brasileira criam-se autores negros autoconscientes de seu papel: a busca de índices negros e de uma ética criativa; a conformação das ideias, os embates internos; a assunção do papel de homens de cultura (no sentido fanoniano) e as variações das ideias de tarefa ou missão; a preocupação com a formação de um público-leitor (idealizado/direcionado) etc.

Esse conjunto de problemas faz com que a partir do $18^{\circ}$ número, em 1995, a série não se apresente apenas como Cadernos Negros, mas se precise o objeto livro como contos ou poemas afro-brasileiros, objetivando deixar mais claro o retorno da produção literária a uma matriz africana, continuada no Brasil. Concorde-se ou não com o acabamento final e os alcances conseguidos pelo grupo, seu retrato e a composição do temário foram talhados com suas próprias mãos. Embora de complexa adaptação ao contexto brasileiro, o pensamento de Frantz Fanon operou como ideia com força social interessante para parcela desse grupo e seus escritores, merecendo pesquisa ainda mais aprofundada para avaliar seus alcances e limites. No entanto, sua apropriação cultural na década de 1980 deixou marcas sensíveis na direção tomada daquele momento em diante. 
1. "Quando Pele negra, máscaras brancas é publicado no Brasil, já estamos em 1983. É a editora Fator, especialista em obras psicanalíticas quem o faz. Ademais, apesar de edição ter sido impressa no Rio de Janeiro, a Fator estava sediada em Salvador, onde também o Movimento Negro Unificado editava seu jornal de circulação nacional" (Guimarães, 2008: 108).

2. Escritor e jornalista, Oswaldo de Camargo é um nome importante da literatura e da imprensa negra. Estreou na literatura com o livro Um homem tenta ser anjo em 1959 e publicou 15 poemas negros em 1961. Ainda nos anos 1960 ligou-se à Associação Cultural do Negro e tornou-se fundador da revista Níger. Em 1972 publicou o livro de contos $O$ carro do êxito e em 1977, junto com outros membros do movimento negro e com a tendência de esquerda Convergência Socialista, aliados a Marcos Faermann, editor do jornal alternativo Versus, tornou-se responsável pela a seção AfroLatino-América; em 1978 foi co-fundador do coletivo de escritores negros paulistanos Quilombhoje e da série Cadernos Negros, e publicou também a novela $A$ descoberta do frio. Em 1987 publicou o livro analítico $O$ negro escrito, acerca do negro na literatura brasileira. Trabalhou como jornalista para $O$ Estado de S. Paulo e o fornal da Tarde. Atualmente, está ligado ao $\mathrm{Mu}-$ seu Afro-Brasil de São Paulo.

3. Inicialmente a equipe da seção AfroLatino-América era composta, além de Camargo, pela jornalista Neusa Maria Pereira, por Hamilton Bernardes Cardoso [Zulu Nguxi] e Jamu Minka (ambos eram jornalistas formados pela USP e viriam a ser colaboradores frequentes de Cadernos Negros, especialmente o segundo, que se tornou membro do Quilombhoje nos anos 1980), além de outros ativistas que, de arti- culistas eventuais, se tornaram permanentes. Até outubro de 1979, foram publicadas matérias sobre a história da imprensa e da literatura negra no Brasil; entrevistas com personalidades artísticas e políticas (o ator Grande Otelo, o político Adalberto Camargo, a política Dilce Pires, a ativista política e cultural Thereza Santos, o membro da Frente Negra Francisco Lucrécio); artigos sobre a história de associações negras antigas (Frente Negra, ACN, Vai-Vai) e novas, surgidas naquela década (Sociedade de Intercâmbio Brasil África/ Sinba, Centro de Cultura e Arte Negra/ Cecan, Festival Comunitário Negro Zumbi/Feconezu, Associação Casa de Arte e Cultura Afro-Brasileira/Acacab); textos destinados à difusão de ideias sobre a organização política negra em países africanos e nos EUA, notadamente através dos antigos exilados Abdias do Nascimento e Thereza Santos; ou, ainda, notícias sobre a vida negra no Brasil, angulada pela discriminação, pela revisão histórica de eventos, a questão da mulher negra ou a participação na cultura e política (Silva, 2011: 292-305).

4. Vale lembrar que Ortiz preparou nos anos 80 um volume dedicado a Fanon para a Coleção Grandes Cientistas Sociais da Ática, que infelizmente não foi publicado, por razões desconhecidas. Mas esse interesse demonstra que Florestan Fernandes já conhecia o trabalho de Fanon e sua contribuição para as ciências sociais, uma vez que ele era o diretor da coleção.

5. A equipe do jornal negro paulistano $O$ Clarim d'Alvorada, fundado por Correia Leite e Jayme de Aguiar, a partir de 1924 conseguiu um colaborador baiano chamado Mário de Vasconcelos, que traduzia o material produzido nos EUA. Leite não 


\section{Frantz Fanon e o ativismo politico-cultural negro no Brasil}

especifica como Vasconcelos conseguia esse material. Mas através desse contato eles descobriram Marcus Garvey e publicaram traduções no jornal de $O$ mundo negro (cf. Leite \& Cuti, 1992: 77-81).

6. Em 1947 o poeta cubano Nicolás Guillén esteve em São Paulo e foi recepcionado por Correia Leite e outros intelectuais negros (Leite \& Cuti, 1992: 138-139); Leon Damas, um dos fundadores do movimento da Negritude, segundo a entrevista que me concedeu Oswaldo de Camargo, organizou sua Nouvelle Somme de Poésie Du Monde Noir (1967) com poetas negros brasileiros, em função de seus contatos com a Associação Cultural do Negro de São Paulo. Relembrando os anos 1960, Camargo afirmou: "[...] Naquele tempo, não. Você não conhecia a África. A África que você tinha era a África literária. Vamos situar em 1960. Então, a África começa a se agitar. Começa a começar o movimento de independência na África. Aí chegam de Angola alguns rapazes que chegam refugiados. Eram dois, pelo menos. Um deles era o, me lembro muito bem, Paulo Matoso. Eles vêm com alguns livros africanos. Primeira vez que nós vimos alguns livros vindos da África! Primeira vez, pelo menos para mim, que eu deparo um homem negro africano. E foi mediante o Paulo Matoso, que me deu um livro da Noêmia [Abranches de Souza], que era uma poetisa de Moçambique, que eu talvez seja um dos primeiros autores que escreveu sobre um poeta africano [no jornal Níger, da ACN]" (cf. Silva, 2011: 188-189).

7. No Rio de Janeiro, através do padre negro Olímpio de Castro, das Irmandades de Nossa Senhora do Rosário dos Homens Pretos e de São Benedito, os membros do Clarim d'Alvorada conheceram Robert Abbott, diretor fundador do Chicago Defender, um dos mais importantes jornais da imprensa negra americana, em visita ao Brasil (cf. Leite \& Cuti, 1992: 78-79).
8. A Associação Cultural do Negro foi criada em 1954 por ativistas negros paulistanos como José Correia Leite, José de Assis Barbosa, Geraldo Campos de Oliveira e outros. Suas atividades começaram em 1956 e tiveram até 1964 um momento de apogeu. A ACN publicou a série Cultura Negra, voltada para debates acadêmicos sobre o grupo social negro, bem como os jornais Níger e Mutirão. Encerrou suas atividades em 1976. A associação é mencionada por Florestan Fernandes (1978), Clóvis Moura (1983) e Miriam Ferrara (1986), sendo que esses autores discutem rapidamente aspectos da organização e/ou utilizam os depoimentos de seus membros e jornais como fontes. A ACN mereceu ainda menção em um estudo de George Reid Andrews (1998), em uma apresentação em congresso por Petrônio Domingues (2007), em um capítulo de tese, em diferentes citações e em meus trabalhos anteriores (2011 e 2012). Algumas vezes é referida em Regina Pahim Pinto (1993) e em Joana Maria Ferreira da Silva (1994). O que sobrou de seu arquivo encontra-se na Universidade Federal de São Carlos (UFSCar).

9. Em 1978, os escritores e ativistas Cuti e Hugo Ferreira criaram uma antologia anual de contos e poemas chamada Cadernos Negros. Em 1980, os dois e mais Oswaldo de Camargo, Mário Jorge Lescano, Paulo Colina e Abelardo Rodrigues formaram o grupo de intelectuais negros denominado Quilombhoje, que passou a representar e se responsabilizar pelos Cadernos. Em 1982 o grupo se alterou sensivelmente, passando a ser composto por Cuti, Esmeralda Ribeiro, Márcio Barbosa, Jamu Minka, Abílio Ferreira, Sônia Fátima Conceição, Oubi Inaê Kibuko e Míriam Alves. Atualmente, os responsáveis pela série em atividade são Barbosa e Ribeiro. Os Cadernos e o Quilombhoje foram estudados por Bernd (1987), Antônio (2005), Souza (2005), Castro (2007) e Silva (2011). 
10. Paulistano, nascido em 1959 , formado em filosofia (USP), Barbosa também é desenhista e escritor. Desde 1982 é membro do Quilombhoje Literatura e atualmente é um dos coordenadores da série Cadernos Negros, onde publicou poemas, contos e artigos. Em 1987 publicou o romance Paixões crioulas. No ano 2000 teve um conto seu selecionado para a antologia $O s \mathrm{cem}$ melhores contos brasileiros do século $X X$, organizada por Ítalo Moriconi para a editora Objetiva.

11. Prosseguindo: "Precisamos perder o hábito, agora que estamos em pleno combate, de minimizar a ação de nossos pais ou de fingir incompreensão diante de seus silêncios ou de sua passividade. Eles se bateram como puderam, com as armas que então possuíam, e se os ecos de sua luta não repercutiram na arena internacional, cumpre ver a razão disso menos na ausência de heroísmo que numa situação internacional fundamentalmente diferente. Foi necessário que mais de uma tribo se rebelasse, mais de uma manifestação reprimida para que pudéssemos hoje erguer a cabeça com esta confiança na vitória" (Fanon, 1979: 172).

12. "[...] Concedo que no plano da existência o fato de ter havido uma civilização asteca não altera muito o regime alimentar do camponês mexicano de hoje. Concedo que todas as provas que pudessem ser dadas da existência de uma prodigiosa civilização songhai não mudam o fato de que os songhai de hoje são subalimentados, analfabetos, vivem entre céu e água com a cabeça vazia, os olhos vazios [...] Inconscientemente, talvez, os intelectuais colonizados, não podendo enamorar-se da história atual de seu povo oprimido, não podendo admirar sua presente barbárie, deliberaram ir mais longe, mais fundo, e foi com alegria excepcional que descobriram que o passado não era de vergonha, mas de dignidade, de glória e de solenidade. A reivindicação de uma cultura nacional passada não reabilita apenas; em verdade justifica uma cultura nacional futura" (Fanon, 1979: 173-175).

13. "Numa primeira etapa, o intelectual colonizado prova que assimilou a cultura do ocupante. Suas obras correspondem exatamente às dos seus colegas metropolitanos. A inspiração é europeia e podese facilmente vincular essas obras a uma corrente bem definida da literatura metropolitana" (Fanon, 1979: 184).

14. "Numa segunda, o colonizado sofre um abalo e resolve recordar. Este período corresponde aproximadamente ao mergulho que acabamos de descrever [...] Velhos episódios da infância surgirão do fundo da memória, velhas lendas serão reinterpretadas em função de uma estética de empréstimo e de uma concepção do mundo descoberta sob outros céus. Algumas vezes essa literatura de pré-combate será dominada pelo humor e pela alegoria. Período de angústia, de mal-estar, experiência de morte, experiência também da náusea. Vomita-se, mas já por debaixo engatilha-se o riso" (Fanon, 1979: 184188).

15. "Enfim, num terceiro período, chamado de combate, o colonizado depois de ter tentado perder-se no povo, perder-se com o povo, vai, ao contrário, sacudir o povo. Em vez de privilegiar a letargia do povo, transformar-se em despertador do povo. Literatura de combate, literatura revolucionária, literatura nacional" (Fanon, 1979: 185).

16. "O intelectual colonizado que retorna a seu povo através das obras culturais comporta-se de fato como um estrangeiro. Por vezes não hesitará em valer-se dos dialetos para manifestar sua vontade de estar o mais perto possível do povo, mas as ideias que exprime, as preocupações que o habitam não têm nada em comum com a situação concreta que conhecem os homens e as mulheres de seu país [...]Querendo ajustar-se ao povo, ajusta-se ao revestimento visível" (Fanon, 1979: 185). 


\section{Frantz Fanon e o ativismo politico-cultural negro no Brasil}

17. "Este racismo que se quer racional, individual, determinado pelo genótipo e pelo fenótipo se transforma em racismo cultural. O objeto do racismo não é mais o homem particular, mas uma forma de existir [...]" (Fanon, 2001: 40. Tradução minha).

18. "Quando aplico a categoria 'intelectual negro' à realidade brasileira, vejo a necessidade de respeitar as devidas diferenças de proporção, o mesmo ocorrendo com noções como 'luta política', já que a luta política africana pressupõe a tomada do aparelho de Estado. Essa noção de intelectual negro inclusive, para o caso brasileiro, é mais metodológica do que real, já que uma reivindicação de especificidade como essa exigiria que constasse de algum programa, já que deve ser deliberada e consciente e exigiria, por outro lado, um reconhecimento por parte da sociedade, pois só isso a legitimaria. Ainda seguindo Fanon, intelectual é aquele que abraça em si as contradições e o que se faz voz do povo, coisa que exige uma potencialidade criadora e crítica, conhecimento e visão profundos, atributos que só podem ser adquiridos através da dedicação constante, do debate sistemático e do reconhecimento honesto da própria ignorância. Assim sendo, enquanto os homens de cultura permaneceram preocupados em aparentar uma importância excessiva em relação ao trabalho que são capazes de desenvolver, só poderemos falar em 'intelectual negro' no sentido figurado" (Barbosa, 1987: 122).

19. “[...] se existe alguma característica marcante na literatura negra é exatamente o fato extremamente rico de a obra vir assinalada pelas cicatrizes que a existência numa sociedade discriminatória impõe ao autor [...] Então se a literatura pode e deve ter alguma finalidade exterior, esta consiste, no nosso caso, em tornar visível este acúmulo de experiências opressivas, colaborando dessa maneira para sua extirpação" (Barbosa, 1987: 131).

20. O trecho de Fanon está em "Racismo e cultura".

21. Trechos gravados por mim da palestra e das intervenções de Cuti durante o I Encontro dos Cadernos Negros: ferramentas para excelência na avaliação dos textos, Sindicato dos Professores do Estado de São Paulo, São Paulo, 5 de julho de 2008.

22. Florentina de Souza chamou atenção para este aspecto: "Vale ressaltar, no entanto, que existe uma forte consciência de missão a cumprir - um desejo 'pedagógico' de contribuir para que outros afro-brasileiros despertem a atenção para a necessidade de lutar contra o racismo e a discriminação e de reverter os mecanismos étnicos-segregadores utilizados pela sociedade brasileira nas suas práticas e discursos. Essa espécie de 'missão' justifica-se pela urgência de desconstruir as imagens seculares, negativas e inferiorizantes dispostas pelos sistemas de representação e que são assimiladas e introjetadas por 'brancos' e 'negros'. Acrescente-se, ainda, o empenho de conscientizar negros e não-negros da fragilidade do mito da democracia racial no Brasil, apontando as implicações deste discurso para a continuidade na estruturação do poder e na sedimentação das desigualdades e injustiças sociais. Com tal objetivo, fazem uso de termos como conscientizar, reflexão, mobilizar, organizar, resgatar, lutar, combater, palavras de ordem que se repetem em artigos do fornal do $M N U$ e em poemas e contos dos $C N$ " (Souza, 2005: 64). 
ALBERTI, Verena e PEREIRA, Amílcar Araújo (orgs.). Histórias do movimento negro no Brasil: depoimentos ao CPDOC. Rio de Janeiro: Pallas/ CPDOC-FGV, 2007.

ANDREWS, George R. Negros e brancos em São Paulo (1888-1988). Bauru: Edusc, 1998.

ANTÔNIO, Carlindo F. Cadernos Negros: esboço de análise. Tese [Doutorado]. Campinas: IEL/Unicamp, 2005.

BARBOSA, Márcio. Questões sobre a literatura negra. In: Reflexões sobre a literatura afro-brasileira. São Paulo: Conselho de Participação e Desenvolvimento da Comunidade Negra, 1985.

A forma escura. In: Corpo de negro, rabo de brasileiro. Rio de Janeiro: Edição dos Autores, 1986.

O sentido da literatura negra, sob uma abordagem fanoniana. In: Criação crioula, nu elefante branco. São Paulo: Imprensa Oficial, 1987 (Trabalho apresentado no I Encontro de Poetas e Ficcionistas Negros Brasileiros).

Frente Negra Brasileira: depoimentos. São Paulo: Quilombhoje, 1998.

Entrevista concedida a Mário Augusto M. da Silva e Vinebaldo Aleixo de Souza Filho em 17/4/2010, em São Paulo.

\& RIBEIRO, Esmeralda. Cadernos

Negros três décadas: ensaios, poemas, contos. São Paulo: Quilombhoje/Seppir, 2008.

BASTOS, Elide R. \& RÊGO, Walquíria D. L. Intelectuais e política: a moralidade do compromisso. São Paulo: Olho d'Água, 1999.

BERND, Zilá. Negritude e literatura na América Latina. Porto Alegre: Mercado Aberto, 1987.
CAMARGO, Oswaldo. O negro escrito: apontamentos sobre a presença do negro na literatura brasileira. São Paulo: Imprensa Oficial do Estado, 1987.

Entrevista concedida a Mário Augusto M. da Silva em 29/7/2007 em São Paulo.

CASTRO, Sílvia L. de. Corpo e erotismo em Cadernos Negros: a reconstrução semiótica da liberdade. Dissertação [Mestrado]. São Paulo: FFLCH/USP, 2007.

DAMAS, Léon G (org.). Nouvelle Somme de Poésie du Monde Noir. Paris: Présence Africaine, n. 57, 1967.

DOMINGUES, Petrônio. Associação Cultural do Negro (1954-1976): um esboço histórico. XXIV Simpósio Nacional de História, São Leopoldo, Unisinos, 2007.

FANON, Frantz. Os condenados da terra. $2^{\mathrm{a}}$ ed. Rio de Janeiro: Civilização Brasileira, 1979.

- Pele negra, máscaras brancas. Salvador: Fator, 1983.

Pour la Révolution Africaine: écrits politiques. Paris: La Découverte, 2001.

FERNANDES, Florestan. $A$ integração do negro na sociedade de classes. São Paulo: Ática, 1978.

FERRARA, Miriam N. $A$ imprensa negra paulista (1915-1963). São Paulo: FFLCH/ USP, 1986.

GUIMARÃES, Antonio S. A recepção de Fanon no Brasil e a identidade negra. Novos Estudos Cebrap, São Paulo, n. 81, jul. 2008.

KÖSSLING, Karin S. As lutas anti-racistas de afro-descendentes sob vigilância do DEOPS/SP (1964-1983). Dissertação [Mestrado]. São Paulo: FFLCH/USP, 2007. 
LEITE, José Correia \& CUTI. $E$ disse o velho militante Fosé Correia Leite. São Paulo: Secretaria de Cultura, 1992.

MOURA, Clóvis. Organizações negras. In: SINGER, Paul \& BRANT, Vinícius Caldeira (orgs.). São Paulo: o povo em movimento. Petrópolis: Vozes/São Paulo: Cebrap, 1983, p. 157-159.

ORTIZ, Renato. Cultura brasileira $\mathcal{E}$ identidade nacional. $2^{\mathrm{a}}$ ed. São Paulo: Brasiliense, 1986.

PINTO, Regina P.O movimento negro em São Paulo: luta e identidade. Tese [Doutorado]. São Paulo: FFLCH/USP, 1993.

ROMANO, Luís A. C. A passagem de Sartre e Simone de Beauvoir pelo Brasil em 1960. Campinas: Mercado de Letras/Fapesp, 2002.
SARTRE, Jean P. Colonialismo e neocolonialismo (Situações, V). Rio de Janeiro: Tempo Brasileiro, 1968.

SILVA, Joana Maria F. da. Centro de Cultura e Arte Negra: trajetória e consciência étnica. Dissertação [Mestrado em Sociologia]. São Paulo: PUC-SP, 1994.

SILVA, Mário A. M. da. A descoberta do insólito: literatura negra e literatura periférica no Brasil (1960-2000). Tese [Doutorado]. Campinas: Unicamp, 2011.

. Fazer história, fazer sentido: Associação Cultural do Negro (1954-1964). Lua Nova, n. 85, 2012.

SOUZA, Florentina de. Afro-descendência em Cadernos Negrose Jornal do MNU. Belo Horizonte: Autêntica, 2005.

VILLAS, BÔAS, Gláucia. Mudança provocada: passado e futuro no pensamento sociológico brasileiro. Rio de Janeiro: FGV, 2006.

\title{
Resumo
}

$\mathrm{O}$ artigo pretende contribuir para o debate sobre a recepção do pensamento do intelectual e ativista Frantz Fanon (1925-1961) no Brasil. Neste sentido, busca acrescentar subsídios a discussões anteriores e confirmar algumas de suas hipóteses, demonstrando que na década de 1980 existiu um momento de aproximação e uso de algumas ideias daquele pensador no ativismo político e cultural negro brasileiro, notadamente entre intelectuais do coletivo Quilombhoje Literatura.

Palavras-chave: Frantz Fanon; ativismo político-cultural negro; intelectuais negros - Brasil.

\begin{abstract}
The article intends to contribute to the debate about the reception of the ideas of the intellectual and activist Frantz Fanon (1925-1961) in Brazil. In this sense, it seeks to offer subsidies to previous discussions and to confirm some of their hypotheses, demonstrating that in the 1980's there was a moment of approach and use of some of Fanon's ideas in Brazilian black political and
\end{abstract}


cultural activism, especially among intellectuals of the group Quilombhoje Literature (1978-).

Keywords: Frantz Fanon; black political and cultural activism; black itellectuals - Brazil.

\section{Résumé}

L'article vut contribuer au débat sur la réception de la pensée de l'intellectuel et militant Frantz Fanon (1925-1961) au Brésil. En ce sens, il cherche à offrir des apports aux discussions précédentes et à confirmer certaines de leurs hypothèses, en montrant qu'aux années 1980 il y a eu un moment de rapprochement et d'utilisation de quelques idées de Fanon par l'activisme politique et culturel noir brésilien, en particulier parmi les intellectuels du collectif Quilombhoje Literatura (1978-).

Mots-clés: Frantz Fanon; activisme politique et culturel noir; intellectuels noirs-Brésil. 